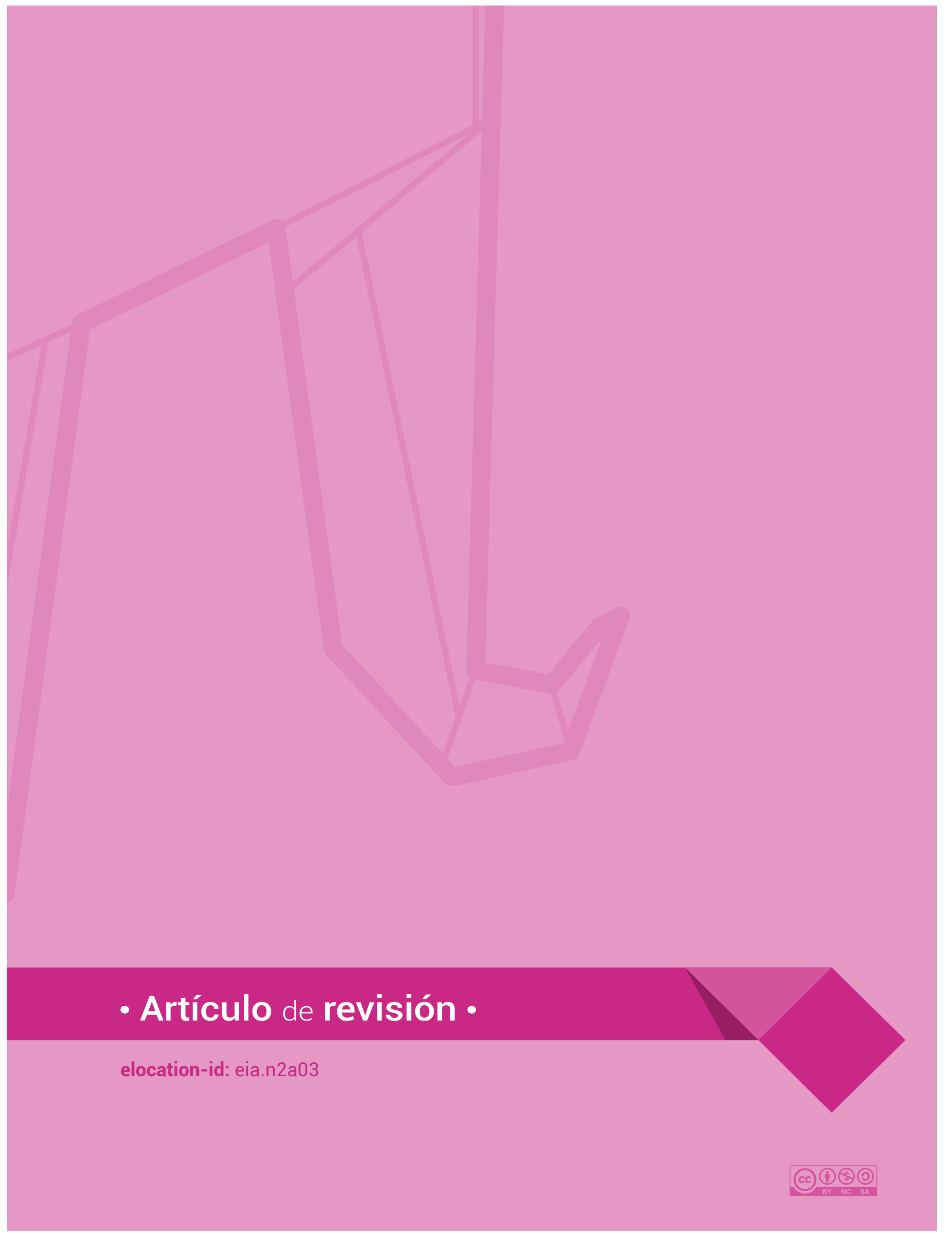




\title{
Auditoría forense: instrumento para fomentar la transparencia en la información financiera
}

\author{
Forensic auditing: a tool to promote financial \\ information transparency
}

Alba Soto-Ortiz'; Laura Ospina-González²

Resumen

El aumento de los delitos económicos y financieros en los últimos años ha fomentado la participación de contadores profesionales en la investigación y resolución de estos casos, puesto que las evidencias y juicios contables son una base fundamental para determinar la existencia o no de la violación de las normas y leyes. La auditoría forense es un tema poco tratado en Colombia y puede marcar la diferencia en el desempeño de la profesión tanto en el sector público como privado, considerando su importancia y apoyo desde la recolección y análisis de pruebas, hasta el peritaje y resolución de los casos de delitos económicos y financieros. La labor de la contabilidad forense, no solamente se destaca en las investigaciones en curso, sino en etapas previas y posteriores al delito, es decir, el contador profesional actúa realizando investigaciones y cálculos que permitan establecer su existencia, y así determinar los detalles de un proceso penal determinado. Este artículo tiene como base principal el análisis de las funciones y procedimientos que el contador público debe tener en cuenta para investigar, evaluar e interpretar los hechos económicos y financieros relacionados con los delitos contables, de acuerdo con la nueva normatividad vigente en Colombia.

Palabras Clave: delito, fraude económico, fraude financiero, investigación.

2 Estudiante, semestre 10, Contaduría Pública, Corporación Universitaria Remington, Manizales, Colombia. Correo electrónico: lauragonza-1992@hotmail.com 
Abstract

The increase of economic and financial crimes in recent years has promoted the engagement of professional accountants to investigate and solve these cases, as accounting evidence and expert opinion are a fundamental basis for determining the existence or absence of violations of rules and laws. Forensic auditing is a rarely discussed issue in Colombia and it can make a difference in the performance of the profession both in public and private sectors, considering its importance and the support it provides, from evidence collection and analysis to expert's reports and resolution of economic and financial crime cases. Forensic accounting plays a role not only in ongoing investigations, but also before and after a crime, that is, a professional accountant conducts inquiries and calculations allowing to establish the existence of a crime, and thus to determine the details of criminal proceedings. This paper aims to analyze the roles and procedures a public accountant must take into account to investigate, evaluate and interpret economic and financial facts related to accounting crimes under the new regulations in force in Colombia.

Keywords: crime, economic fraud, financial fraud, investigation.

\section{Introducción}

Con la adopción de las NIIF (Normas internacionales de información financiera) y las NIA (Normas internacionales de auditoría), se pretende una transformación de la contabilidad en general, tanto en las organizaciones como en el trabajo del contador público, debido a que los elementos que hacen parte de los estados financieros, tales como activo, pasivo, patrimonio, ingresos y gastos, exigen un mismo modelo, en el que la información que se presente contenga credibilidad, claridad y comparabilidad de la misma. La Ley 1314 (2009) en su artículo 1 puntualiza que la información contable, además de las anteriores, contiene otras características:

El Estado, bajo la dirección del presidente de la República y por intermedio de las entidades a que hace referencia la presente Ley, intervendrá la economía, limitando la libertad económica, para expedir normas contables, de información financiera y de aseguramiento de la información, que conformen un sistema único y homogéneo de alta calidad, comprensible y de forzosa observancia, por cuya virtud los informes contables $y$, en particular, los estados financieros, brinden información financiera comprensible, transparente y comparable, pertinente y confiable, útil para la toma de decisiones económicas por parte del Estado, los propietarios, funcionarios y empleados de las empresas, los inversionistas actuales o potenciales y otras partes interesadas (p. 1).

Esta ley tiene en cuenta la transparencia, la cual hay que trabajar desde muchos ángulos, teniendo en cuenta que puede ser vulnerable y manipulable; en las entidades deben existir mecanismos que protejan la aplicación y la utilización de la información, exigir siempre el buen uso de las normas y leyes, no solo en materia contable, también en todos los ámbitos que rodean la operatividad de las mismas. Es evidente entonces que el contador profesional está obligado a realizar buenas prácticas en su cotidianidad, tanto en su trabajo como en su vida personal. El éxito de la información contable depende en gran parte del buen juicio y de los valores con que procede la persona que revisa y aprueba esta información, es el profesional contable quien actuando basado en las NIIF y las NIA, complementa su labor con una auditoría especializada y cuidadosa, pudiendo así prevenir o corregir los hallazgos que se detectan y que pueden perjudicar a las empresas. 
Es evidente entonces que, con la evolución de la economía, en Colombia los profesionales contables no pueden quedar al margen de los cambios, pues la premisa es mantenerse vigente en un mercado tanto nacional como internacional. La globalización exige un modelo contable universal donde los elementos que forman los estados financieros se midan de manera equivalente en cualquier país. Este aspecto permite que la información financiera genere claridad, credibilidad y comparabilidad a nivel mundial y a la vez, tiendan a ser útil para todo tipo de usuarios en cualquier parte del mundo.

Después de las consideraciones anteriores:

Una organización no puede ser competitiva a nivel local sin serlo internacionalmente. Por lo tanto, las empresas que pretendan permanecer en el mercado deberán iniciar su proceso de internacionalización. Asimismo, solo aquellas que sean competitivas a nivel nacional, podrán impulsar con éxito un proceso de internacionalización. Este concepto ha sido utilizado y definido desde diversas ópticas, entre ellas la capacidad de las empresas de un país para crear, producir y distribuir bienes y servicios en los mercados internacionales. En esta entrada a la escena internacional, se distinguen tres fuentes fundamentales del desarrollo de la competitividad internacional: el país, el sector y la empresa (Arroyo, 2011, p. 70).

Significa entonces, que el contador profesional forense debe reorientar su profesión con miras a satisfacer las exigencias del mercado internacional, su labor consiste en la detección de hallazgos en las organizaciones; por lo tanto, es conveniente desarrollar un perfil con bases legales, pero fundamentado en las exigencias tributarias, dado que cometer un error es grave a nivel profesional. El desarrollo, innovación y progreso de la contabilidad forense demanda de la preparación de profesionales hábiles, con capacidad de diseñar planes de trabajo preventivos y correctivos, especializados en el análisis de los hechos económicos, con competencias técnicas para el desempeño de sus funciones, que respondan a la problemática social, a los intereses individuales y generales; en el mismo sentido, la sociedad también exige respuestas y acciones que permitan el mejoramiento de la calidad de vida y que, además, los profesionales tanto de la contabilidad forense como de otras especialidades, puedan mantenerse vigentes en el mercado; estar a la par con la evolución del mundo. Londoño y Saldarriaga (2011) proponen:

Por esta razón, el perfil de un auditor forense apunta hacia una mezcla de contador público, abogado e investigador, ya que en adición a los conocimientos de contabilidad y auditoría habituales, para complementar los requisitos exigidos para desempeñar sus funciones en forma idónea, debe incluir aspectos de investigación legal y formación jurídica, con énfasis en la obtención de pruebas y evidencias, conocimientos en psicología, informática y experticia en la regulación del sector en que se desempeñe profesionalmente. Adicional a estas características de interdisciplinariedad, debe tener cualidades mentales entre las más importantes están: tener una mentalidad investigadora, ser perspicaz, mucha auto-motivación, trabajo bajo presión, mente creativa, habilidades de comunicación y persuasión, habilidad de comunicarse con apego a las leyes, habilidades de mediación y negociación, habilidades analíticas y creatividad para adaptarse a las nuevas situaciones. Como podemos observar, estas características se asocian íntimamente con la investigación de casos al margen de la legalidad, corrupción, crímenes, terrorismo, entre otros de su naturaleza. El auditor forense llega a establecer indicios de responsabilidades penales que con la evidencia obtenida 
pone a consideración del juez correspondiente para que dicte sentencia. Este también debe brindar a las empresas las herramientas necesarias que le permitan la implementación de los controles preventivos y correctivos necesarios para evitar en el futuro posibles fraudes financieros (p. 60).

A lo largo de este artículo de revisión se pretende realizar un acercamiento y dar claridades conceptuales y teóricas frente a la auditoría forense como un instrumento eficaz a la hora de fomentar la transparencia en la información financiera de cualquier organización privada o pública.

El presente artículo científico de revisión se realizó a partir de la consulta de documentos en bases de datos académicas como Scielo, Redalyc Google Académico, y diferentes páginas y repositorios de reconocidas universidades tanto de Colombia como de otros países, eligiendo algunos de acuerdo con el tema de interés, especialmente los referentes a Colombia. La estructura del artículo está basada en categorías tales como la implementación de las normas Internacionales de la información financiera y aseguramiento de la información, auditoría y contabilidad forense y la normatividad en Colombia. Estos temas permitirán conocer la información, las normas, los procedimientos y las estrategias que debe tener en cuenta el contador profesional ante las nuevas exigencias del mercado, que demanda cambios en los procesos, un nuevo enfoque a los mismos y, por ende, un valor agregado a la profesión.

Este artículo pretende despertar una inquietud de lo que es el tema de la investigación del crimen económico y financiero, y así mismo, indagar la importancia de esta especialidad frente a la implementación de las NIA, dado que este profesional, no solo se debe conformar con dar un informe o dictaminar una información económica y contable, sino que en igual sentido, también deberá proporcionar a las autoridades judiciales la seguridad de que esta misma refleja o no la realidad económica de la empresa, siendo partícipe de la lucha contra la corrupción y la falta de transparencia, por medio del ejercicio honesto, responsable y transparente de la profesión.

\section{Resultados}

\section{Decreto 2649 de 1993}

Los estados financieros de las organizaciones, tienen el objetivo de suministrar la información acerca de la situación económica y financiera de las mismas, para así permitir a los usuarios finales tomar las mejores decisiones. La contabilidad y su proceso a lo largo del tiempo nos ha dejado entrever que Luca Pacioli, en su libro Summa de Aritmética, Geometría, Proportionati et proportionalites, expone ciertas reglas de la partida doble, como unos principios fundamentales, tales son: no hay deudor sin acreedor, la suma que se adeuda a una o varias cuentas ha de ser igual a lo que se abona, todo el que recibe debe a la persona que da o entrega, todo valor que ingresa es deudor y todo valor que sale es acreedor y toda pérdida es deudora y toda ganancia acreedora (Hernández, 2012).

Según las consideraciones anteriores, no se encontraba tan distante de la realidad, gracias a estas conceptualizaciones, cada sociedad ha construido su propio proceso contable, que en la actualidad siguen vigentes y que, de alguna manera, garantizan que las acciones administrativas y operativas manejen una coincidencia con las exigencias del mercado. La contabilidad forense necesita estar más acorde con estos conceptos, porque su función va más allá de analizar e investigar un hecho legal, también 
emite juicios que permiten la resolución de hechos legales.

Ante la situación planteada, los principios básicos de la contabilidad permiten según la Ley 1314 (2009) «identificar, medir, clasificar, registrar, interpretar, analizar, evaluar e informar, las operaciones de un ente económico, en forma clara, completa» (Art. 3) y fidedigna. El contador público se encuentra más que inmerso en la aplicación de estos principios, para cumplir su función de garantizar que la información que se procesa, se verifica, se audita, se informa, sea el contexto económico de la empresa, que pueda dar la certeza de que el trabajo realizado está basado en los principios de contabilidad y que se puede confiar totalmente en él.

\section{Normas internacionales de la información financiera (NIIF)}

El mundo vive unos procesos de transformación que generan infinidad de cambios y avances, a los que todos los países deben acogerse para mantener una economía vigente. Se elige adoptar las NIIF y las NIA, para preparar la información financiera y para evaluarla respectivamente. Esto conlleva a un proceso investigativo por parte de los clientes de esta información y los autores de la misma, dado que las brechas entre los principios de contabilidad generalmente aceptados (PCGA), las normas de auditoría generalmente aceptadas (NAGA), las NIIF y las NIA, son bastante amplias, además de que los procesos contables y fiscales tienen marcadas diferencias.

Con referencia en lo anterior, el proceso de internacionalización que ha vivido Colombia ha sido vital para la economía interna y sus miras macroeconómicas externas, y es allí cuando aparece la necesidad de globalizar la información contable. En estos procesos de estandarización muchos países al igual que Colombia, se vinculan y se hacen participes de la adopción y adaptación de las normas internacionales, para garantizar los tratados y mercados y de esta manera incentivar la inversión económica entre países.

\section{Normas internacionales de auditoría (NIA)}

Las normas de auditoría generalmente aceptadas (NAGA) son los principios fundamentales que regían en Colombia el desempeño de los auditores, aunque estas eran superficiales y quedaban cortas en el desarrollo de la auditoría, además, no aportaban las bases ni los elementos de juicio necesarios en la misma.

En el artículo 7 -De las normas de auditoría generalmente aceptadas-, de la Ley 43 (1990), se relacionan las cualidades profesionales del contador público, y nombra las siguientes normas de auditoría:

- Normas personales.

- Normas relativas a la ejecución del trabajo.

- Normas relativas a la rendición de informes.

- Código de ética (p. 3).

Estas normas debían ser aplicadas tanto a la conducta personal, como a la realización de la labor desempeñada por el auditor, de tal manera que su trabajo generara una revisión, evaluación e informes de alta calidad y confiabilidad.

Por esta razón, en el artículo 5 de la Ley 1314 (2009), las NIA, se conceptualizan como un "conjunto de normas de auditoría, de control de calidad y de aseguramiento de la información 
que aplicadas correctamente permiten a los auditores proferir una opinión acerca de la información contable analizada y evaluada de acuerdo a los parámetros actuales en Colombia» (p. 3).

La dinámica de la globalización genera la necesidad de contar con información financiera razonable y con parámetros de calidad en el aseguramiento de la información financiera auditada; permite la coherencia normativa y complementariedad entre los estándares contables y de auditoría; subsana la insuficiencia de las normas de auditoría generalmente aceptadas en Colombia; satisface la necesidad de contar con un marco normativo homogéneo aplicable tanto a firmas como a profesionales independientes; el estándar internacional no entra en conflicto con las normas de la revisoría fiscal, pues estas solo aplicarían a dicha figura en lo que respecta a una de sus funciones, la de revisar la razonabilidad de la información financiera (Ochoa, Zamarra y Castaño, 2012, p. 16).

Tal como se ha visto, los auditores se deben apropiar tanto de las normas anteriores como de las nuevas; el impacto en la elaboración, la presentación, el análisis de datos, la aplicación de herramientas financieras y de auditoría, y otros cambios que trae consigo esta implementación, brindan elementos para una mejor toma de decisiones tanto de inversión como de financiación, permite a las empresas proyectarse a nivel internacional, y hasta ayuda a los usuarios a implementar medidas preventivas, antes que correctivas o reactivas.

\section{Contabilidad y auditoría forense}

La contabilidad se encarga de estructurar un sistema de información que mide e interpreta hechos económicos que, al ser revelados en los estados financieros, diferentes usuarios pueden tomar las mejores decisiones, por este motivo las leyes penales las toman como apoyo en las investigaciones de este tipo, considerando que son de gran utilidad en la resolución de actos fraudulentos o ilícitos. Cabe anotar que estas pruebas están sujetas a la normatividad penal, disciplinaria y contable, y deben ser completas, confiables, sin sesgos, que correspondan a hechos reales y que sean verificables.

La Auditoría Forense nos brinda las herramientas necesarias para minimizar el riesgo de fraude financiero por medio de una metodología que se basa en una actitud ética, para así acabar con la impunidad de aquellos delincuentes de cuello blanco, ubicados en la alta gerencia e incluso en la dirección política de nuestro país, así como de empleados corruptos, que llevan a la bancarrota a las organizaciones (Sadder, 2013, p. 33).

Ante la situación planteada, la auditoría forense aparece como una especialidad de la contaduría que ha avanzado notablemente en los últimos tiempos y se encarga de investigar, analizar, evaluar e interpretar una información financiera y económica, permite al contador público, reunir y presentar información financiera, contable, legal, administrativa e impositiva, de tal forma que pueda ser aceptada y analizada por un juez, para tomar decisiones que permitan fallar en contra o no, de los acusados de un crimen económico, sus informes y reportes dan como resultado la transmisión de una información que permite llegar al desenlace de un caso legal.

Un auditor interno o externo, puede tener mucha experiencia en los procesos de evaluación de control interno y de presentación de informes con valor agregado ante el ente que contrata sus servicios, pero para el caso de investigaciones de fraudes y delitos requiere conocimientos en el campo judicial, especialmente en el 
levantamiento de indicios y evidencias, las cuales se deben relacionar con delitos tipificados en los códigos penales, para que fácilmente se puedan convertir en pruebas que requiere la justicia para sus sentencias. La Auditoría Forense, es de hecho, una herramienta muy valiosa en la aplicación de la justicia, y debe por lo tanto ser un proceso legal que se deriva de una serie de protocolos, como son la autorización de una entidad oficial (Fiscalía, Procuraduría, Contraloría, una Corte Civil o Criminal, etc.). Este procedimiento como es de tipo investigativo y lo que se persigue es la judicialización y a la postre la penalización o exoneración, debe ser ejecutado bajo Normas Internacionales de Auditoría Especial, para evitar cometer errores que por insignificantes que puedan ser, anulen totalmente la investigación y el caso en la Corte o tribunal de Justicia pueda ser desestimado por un juez (Fonseca, 2009, p. 17).

Después de las consideraciones anteriores, en la actualidad los hechos delictivos son más organizados y tecnificados, lo que hace preciso una formación más profunda e integral del contador profesional forense, que establezca las pautas, medios y acciones, para detectar presuntos delitos económicos, corrupción, estafas, desfalcos, fraudes, lavado de activos, falsas economías, entre otras, previo análisis de pruebas y evidencias que sirvan como medio de apoyo para los que finalmente deciden si existe o no un delito.

Se espera que el auditor forense tenga una base fuerte en el manejo contable, acompañados con conocimientos sólidos de auditoría, valoración de riesgos y control; además, debe demostrar un conocimiento del ambiente legal necesario para su trabajo como litigante y tener una serie de habilidades para una ejecución eficiente en su labor como la comunicación, las habilidades de detective y de litigante audaz (Rodríguez, 2009 citado por Ramírez y Reina, 2013, p. 187).
Con referencia en lo anterior, los corruptos progresan en su pericia para cometer delitos económicos, por eso las empresas adaptan diferentes sistemas de control, con la intención de anteponerse al paso de este flagelo que siempre está latente al riesgo, frente a la posibilidad del fraude financiero y económico.

\section{¿Por qué la aplicación de la auditoría forense?}

La contabilidad forense se originó cuando en los años 70 y 80 ya se empezaron a descubrir delitos que tenían que ver con las finanzas, surgiendo la necesidad de investigar y resolver los mismos. Su aplicación se fue ampliando dado que los delitos económicos se hacían cada vez más frecuentes y más grandes, por lo tanto se empezaron a desarrollar técnicas, instrumentos y normas de investigación, iniciando allí una oportunidad para los contadores públicos que les exigía no solamente que fueran expertos en el área financiera y económica, también debían adquirir conocimientos en el área legal, jurídica, de auditoría, desarrollar, además, una visión integral, pericia y responsabilidad, sin dejar de lado la práctica de la ética profesional, considerando que daba fe pública de sus actuaciones y de los hechos que vigilaba y certificaba. Convirtiendo su trabajo e investigaciones, en material probatorio primordial para la resolución de este tipo de casos, tan comunes en el mundo.

La Auditoría Forense es muy usada en otros países, tanto así, que en los Estados Unidos de América ya se ha conformado la Asociación de Contadores Forenses (en inglés Association of Forensic Accountants - NAFA) que es una asociación profesional de firmas de contabilidad dedicadas a la investigación. Los miembros de esta 
asociación brindan respaldo profesional para las reclamaciones a la industria de seguros y a los clientes en los distintos procesos de litigios. Existe en ese país, Europa y Australia, un sinnúmero de firmas especializadas en lo que ellos mismos se han autodenominado detectives financieros.

En nuestro país hay déficit de profesionales en "Auditoría Forense» y pocas oportunidades de formarse como tal, teniendo que aprender a los «mazazos», cuando ya el fraude está cometido: el dinero no está en caja, el banco nos sobregira cuando en el libro de bancos registra un saldo suficiente, se cobra una factura al cliente el cual muestra recibo de pago de la empresa con sellos y firmas; y otras formas más sofisticadas en colusión (unión del empleado interno con una persona externa para defraudar a la empresa); o de manera más compleja que la Fiscalía ordena la expropiación de la empresa (diferente al lavado de activos en donde la Fiscalía demuestra la conducta punible; en la expropiación es la empresa la que debe demostrar como obtuvo el bien expropiado, en el ente investigador con elementos mínimos procede a expropiar, esta figura así concebida es única en Latinoamérica), Ilega la imputación de estar incursos en lavado de activos, o aparecemos en la famosa «Lista Clinton» de EE. UU., en donde de manera inmediata los bancos nacionales nos suspenden toda relación o simplemente nos citan para explicar una «operación sospechosa» (Pantoja, 2012, p. 249).

En efecto, los casos de corrupción, fraudes, estafa, lavado de activos, y otros delitos económicos y financieros aumentan cada vez, no solo en Colombia, también a nivel mundial, cada día con más frecuencia, los medios de comunicación difunden esta clase de noticia de hechos ilícitos cometidos en las empresas o compañías. Baracaldo y Daza (s.f) opinan que:
Los medios de comunicación y la divulgación de algunos procesos judiciales de connotación nacional, así como los más recientes escándalos de corrupción y otros delitos financieros han resaltado la importancia de contar con pruebas técnicas financieras especializadas que complementan la labor de las autoridades o la defensa. Estas técnicas financieras forenses especializadas se conocen como auditoría forense, que es distinta a la auditoría financiera tradicional. La auditoría forense generalmente se realiza por un equipo de profesionales que requieren de un trabajo multidisciplinario y unas técnicas específicas que garanticen la obtención, autenticidad y custodia de las evidencias.

Los temas de auditoría forense, contabilidad forense y técnicas para la detección y administración del riesgo de fraude, entre otros, aún no han sido incorporados en los planes de estudio de algunos de los programas de contaduría pública acreditados en el país, con la suficiente dedicación y énfasis. Actualmente, solo existen dos programas de especialización en estos temas y algunos cursos o diplomados en otras instituciones universitarias (p. 2).

Al respecto conviene decir que en el mundo han existido casos reconocidos respecto al crimen económico y financiero tales como: Enron, Word Com, Parmalat, Petrolera Yukos, Merek, Xerox, BMW, y en Colombia: Saludcoop, Drogas la Rebaja, Grupo Empresarial Grajales, entre muchos otros. Estos casos han impulsado la emisión de normas y leyes con el fin de mejorar el funcionamiento de los procesos y la calidad de la información, buscando implementar procedimientos más preventivos que correctivo o reactivos. 
Cabe señalar, que en Colombia con la implementación de las NIIF y las NIA, se pretende dar un control a los movimientos financieros en las empresas, tanto a nivel administrativo como operativo, de hecho, en materia penal, también se han sancionado leyes para el manejo y control de este fenómeno actual, en el código penal se encuentran diferentes tipos de penalidades que suscita el cometer algunos de los siguientes delitos económicos o financieros. En sus títulos VII - Delitos contra el patrimonio económico (hurto, extorsión, estafa, fraude mediante cheque, abuso de confianza, defraudaciones, usurpación, del daño), Título IX - Delitos contra la fe pública (falsedad de documentos), Titulo $X$ - Delitos contra el orden económico social (delitos contra el sistema financiero, lavado de activos, contrabando), el Estado Colombiano deja claro que esta es una situación ineludible que necesita toda la atención necesaria para su prevención.

Ahora bien, los delitos económicos tales como la contratación indebida, lavado de activos, tráfico de influencias, abuso de confianza, pasivos inexistentes, soborno, concierto para delinquir, entre otros, son una muestra de las formas de corrupción, sin contar que el avance tecnológico es cada vez mayor y esto ayuda a fortalecer la perpetración de estos crímenes y daños económicos, que a la larga se van haciendo más difíciles de detectar por su tecnificación, allí el auditor forense juega su papel más importante, pues de su pericia, destreza, buen juicio y conocimiento, depende que estos delitos no se queden en la impunidad; ofrecer las herramientas necesarias y correctas que permitan la eficiente toma de decisiones tanto de los jueces como de quienes tengan en su poder estas disposiciones finales de sentenciar o juzgar.
Dado que, la corrupción alcanza un alto nivel de aplicación en todos los ámbitos financieros y económicos de las empresas, tanto privadas como públicas, allí entonces está la posibilidad y la oportunidad para que el contador público encuentre una opción de desempeño de sus funciones en el mercado.

Vale la pena destacar que con el estatuto anticorrupción el Estado ha querido establecer lineamientos y penalizar la corrupción en diferentes sectores públicos y definir algunos órganos de control que le faciliten la investigación y observación de los posibles casos criminales. La corrupción y la malversación de fondos en los entes públicos son un tema recurrente en Colombia, y el sector político especialmente ha sido el talón de Aquiles para la economía; la fuga de dineros que allí se presenta es una constante, la corrupción ha estado presente siempre en este ámbito, las grandes maquinarias políticas han sido las mismas y siempre han manipulado las leyes y las reglas de juego, es evidente la falta de transparencia y el buen uso de los recursos.

Este estatuto anticorrupción desarrolla un sistema que trata de evitar los actos de corrupción, para generar confianza, no solo en las personas que desarrollan sus cargos públicos, sino también en las funciones y cargos que desempeñan. Se busca que los funcionarios públicos y privados desarrollen el ejercicio de sus labores con ética y profesionalismo, antes de tener que optar por la aplicación de la auditoría forense, como un medio preventivo o como correctivo, en la investigación de sus actuaciones. 


\section{Discusión}

\section{El Contador Profesional y su enfoque frente al delito económico y financiero}

Generalmente se requieren de los siguientes atributos para un auditor forense «una mentalidad investigadora; una comprensión de motivación; habilidades de comunicación, persuasión y una habilidad de comunicar en las condiciones de ley; habilidades de mediación y negociación; habilidades analíticas; creatividad para poder adaptarse a las nuevas situaciones» (Pantoja, 2012, p. 249).

De hecho, el ideal de trabajo sería que los seres humanos actuaran conforme a la normatividad, siguiendo las leyes y que de manera responsable cumplieran con todas y cada una de las buenas prácticas. Pero desafortunadamente esta es una utopía, puesto que cada vez más y debido a la misma situación de inequidad que se vive en el mundo entero, las personas buscan la forma según ellos, más fácil de conseguir sus metas. El comportamiento y la conducta del ser humano está influenciado por factores sociales, culturales o biológicos, que lo hacen actuar de una u otra manera. Existen causas motivacionales que lo impulsan a cometer un delito, puede ocurrir también que este tipo de personas tengan la oportunidad de hacerlo, dado que cuentan con el acceso a la información, a los recursos, a las técnicas y al conocimiento de la organización; es decir, sacan provecho de la oportunidad, sin contar con que son personas que se han ganado la confianza de los administradores y de estas ventajas se aprovechan para cometer faltas en contra de la empresa.
En la prevención, se debe permanecer siempre alerta ante cualquier circunstancia (oportunidad) que pudiera facilitar y permitir que se cometa un delito patrimonial; es decir reconocer los delitos patrimoniales que podrían presentarse en la organización en un futuro. Tiene como objetivo identificar los riesgos potenciales de fraude a los que puede estar expuesta una organización y elaborar planes y programas de acción para minimizarlos (Funes y Najera, s.f, p.12).

Sin duda, si se habla de un profesional, en cualquiera que sea su área, uno de los valores más importantes que debe aplicar es la ética, teniendo en cuenta que de esta depende el correcto accionar de todas las personas. El actuar profesional es necesario que esté impulsado por la honestidad, la sinceridad, la objetividad, la responsabilidad, la confidencialidad, el proceder conforme a las leyes y normas, entre otros valores que enriquecen no solo a los seres humanos como personas, sino también como profesionales, que generan de esta manera un valor agregado al desempeño de sus funciones.

\section{La contabilidad Forense en la implementación de las NIA}

Indudablemente, si los auditores cumplen con rigurosidad los nuevos requisitos y pautas establecidas en las nuevas normas internacionales, se llevarán a cabo auditorías de mayor calidad, que dotarán a la información financiera de un mayor control hacia la transparencia necesaria para luchar contra las crisis sucesivas como la actual. «[...] Además, desde el ámbito profesional se debe contribuir al mejor ejercicio de la práctica, mediante una adecuada preparación y entrenamiento de los auditores, así como de los oportunos controles de calidad de 
sus trabajos» (Martínez, Ramírez, Montoya y Fernández, 2010, p. 22).

En relación con esto último, otro valor agregado que puede generar el contador público forense a su profesión, es el de participar activamente en los procesos de actualización de la profesión como tal, no solo limitarse a investigar, analizar, evaluar, interpretar la información contable y emitir juicios y conceptos confiables y completos, debe ir a la par con los cambios en la normatividad contable, financiera, penal y civil, que le permitan mantenerse vigente en el mercado; es importante que identifique cuál es la normatividad vigente, los procesos, métodos y técnicas, tanto locales como internacionales a implementar o establecer, de modo que le permitan no solo detectar errores o fraudes intencionales, sino también que le ayude a desarrollar habilidades para prevenir delitos provenientes de figuras ilícitas, haciendo un buen uso de las NIA, que tengan que ver con el tema de riesgo. Para Badillo (2008):

El interrogante surge debido a que con la implementación en el país de las NIA, el contador público forense debe cambiar su proceder respecto al desarrollo de su profesión, identificar las normas, procedimientos y estrategias que se deben tener en cuenta, ante las nuevas exigencias del mercado, pues si los nuevos estándares requieren la información financiera más amplia y abierta, la tarea investigativa del contador público forense va a ser más fácil y le permitirá la recopilación de prueba con mayor comodidad. Su profesión tiene una nueva visión y debe disponer de elementos técnicos para brindar un mejor servicio (p. 5).

Por ello, se hace necesario que cuando se detectan irregularidades el auditor forense debe establecer la incidencia que estos tienen sobre los estados financieros y sobre la estabilidad financiera de la organización, es su obligación dar a conocer dichos hallazgos a las personas interesadas, para que ellos tomen las medidas en la resolución de los casos.

No se espera, ni es posible, que el auditor reduzca a cero el riesgo de auditoría. En consecuencia, el auditor no puede obtener una seguridad absoluta de que los estados financieros estén libres de incorrección material, debido a fraude $o$ a error. Existen limitaciones inherentes a la auditoría que tienen como resultado que la mayor parte de la evidencia de auditoría, a partir de la que el auditor alcanza conclusiones y sobre la que basa su opinión, sea convincente pero no concluyente. Las limitaciones inherentes a la auditoría surgirán de: la naturaleza de la información financiera; la naturaleza de los procedimientos de auditoría; y la necesidad de que la auditoría se realice en un plazo de tiempo y a un coste razonable. Cada NIA aplicable identifica procedimientos de auditoría específicos para permitir mitigar el efecto de estas limitaciones inherentes (Herreros, 2010, p. 74).

En lo que se refiere a las NIA, son la herramienta a través de las cuales, el auditor forense puede basar su práctica, y que le permiten establecer los factores de riesgo que se deben tener en cuenta para determinar si existe o no, un delito económico, y la forma cómo los puede detectar, por mencionar algunas:

NIA 200 - Objetivos Generales y conducción de una auditoría: El auditor debe expresar si los estados financieros están preparados razonablemente, su responsabilidad es el análisis de los mismos.

NIA 240 - Responsabilidades del auditor frente a fraude en una auditoría de estados financieros: previene acerca de las incorrecciones que pueden presentar los estados financieros ya sea por fraude o por error. 
NIA 300 - Planificación de una auditoría de Estados Financieros: una efectiva planificación para que la auditoría sea realizada de manera rápida, oportuna y eficiente, y de esta forma sea más factible el hallazgo de situaciones indebidas o incorrectas.

NIA 315 - Identificación y análisis de los riesgos de desviaciones significativas mediante la comprensión de la entidad y de su entorno: conocer todas y cada una de las partes que componen la organización y verificar cuáles son las actividades y los rubros que pueden ser susceptibles a incorrección material y en ellos profundizar su trabajo.

NIA 320 - Importancia relativa y materialidad: reconocer los hechos con mayor riesgo en todo el proceso de auditoría.

NIA 330 - Respuestas del auditor a los riesgos evaluados: suministrar las debidas recomendaciones, ya sean preventivas o correctivas, acerca de las situaciones que ocasionan riesgo en la empresa.

NIA 402 - Auditorías a entidades que utilizan organizaciones de servicios: conocer y entender el entorno de la empresa referente a los contratos de servicios.

NIA 500 - Elementos de juicio en las auditorías: responsabilidad que tiene el auditor de obtener la evidencia que permita dar una opinión lo suficientemente ajustada a la realidad económica de la empresa, utilizar los medios y las herramientas que proporcionen la suficiente información acerca de la entidad auditada, para obtener unas conclusiones ajustadas razonablemente (Sánchez, 2011, pp. 15-16).

Las posibilidades de declaración incorrecta en las afirmaciones, observaciones o declaraciones de los estados financieros, se analizarán mediante la consideración específica del riesgo inherente, riesgo de control y riesgo de detección. Con base a la consideración que el auditor haga de estos factores de riesgo, establecerá su estrategia de auditoría y el alcance de las pruebas que realizará para lograr el grado de seguridad deseado; es decir, en base a las afirmaciones de los estados financieros y considerando los ciclos de negocios se establecen los objetivos generales y específicos de cada tipo de operación y del saldo final en la cuenta relacionada (González, Giménez, Puyó, Padovan, Stefanon y Villani, 2011, p.12).

\section{Responsabilidad del auditor frente a los crímenes económicos $y$ financieros}

Frecuentemente se piensa que el auditor tiene la responsabilidad de descubrir los hechos fraudulentos en sus revisiones, pero realmente la responsabilidad recae sobre los procedimientos y las personas que realizan los procesos, para proporcionar una información contable final. Por esto la importancia de reconocer e identificar previamente cuáles son los riesgos potenciales que pueden presentarse en una organización antes de ejecutar la auditoría.

La confiabilidad de los informes financieros, inherente al principio de transparencia, no depende únicamente de los estándares contables que se utilicen para la preparación de la información financiera ni de los que se apliquen para las labores de auditoría. La confiabilidad de los informes financieros debe ser un objetivo de las empresas, que depende, entre otras cosas, de un adecuado sistema de control interno.

Como todo objetivo, los informes financieros confiables se pueden ver impactados por riesgos; 
para contrarrestarlos, se hace necesario que las organizaciones identifiquen y analicen los eventos que pudiesen afectar la transparencia y confiabilidad de la información (Baracaldo, 2011, p. 1114).

Por su parte, es primordial que el auditor tenga certeza acerca de la confiabilidad en las transacciones realizadas en las organizaciones, que los comprobantes y registros contables estén reflejados fielmente en los estados financieros; si están elaborados en forma incorrecta con errores importantes, el auditor está obligado a abstenerse de emitir una opinión favorable o sin salvedades, puesto que esto puede ocasionar desconfianza y falta de credibilidad de su trabajo, y puede incluso verse como cómplice de las defraudaciones o alteraciones de los informes financieros.

También, ante la realización de una auditoría previamente es prioritario reconocer cuáles pueden ser los factores o riesgos a los que está expuesto la empresa y cuáles son las medidas de control o cómo funciona el sistema de control interno, que permite reducir estos riesgos. Conocer la situación financiera, el origen de los ingresos, la normatividad que la regula, conocer el personal que realiza las actividades más riesgosas, los sistemas de información y comunicación que se utilizan; todo esto proporciona un acercamiento con los aspectos que pueden tener mayor influencia o incidencia en los resultados de la auditoría. Maiola (2013) afirma:

El contador sea en su rol de auditor externo o interno, se enfrenta a situaciones en las que, al prestar servicios a las empresas, el empresario le reclama valor agregado a su tarea, más allá de la mera teneduría de libros, sin embargo, el contador que emite opinión sobre los Estados Contables se enfrenta a dos situaciones frente a una sospecha de Fraude: a) tener que investigar a personas que, a fin de cuentas, son los que le están pagando sus honorarios. Esta situación pone en tela de juicio su independencia $o, b$ ) profundizar la investigación, descubrir el fraude, lo que seguramente conducirá a que sea inmediatamente reemplazado por otro colega (p. 147).

\section{Aspectos más sensibles en las empresas frente al delito económico y financiero}

Para las empresas, es fundamental conocer y estar siempre preparadas para afrontar los riesgos a los que pueden estar expuestos y que son inherentes a las actividades desarrolladas, y así convenientemente definir políticas de prevención.

Existen factores múltiples que pueden generar verdaderos caldos de cultivo que llevan a las organizaciones a estar expuestas a un nivel de vulnerabilidad muy alto, y que en muchas ocasiones culminan en quebrantos en su contra. Entre esos factores podemos mencionar los siguientes: ausencia de una cultura de ética del personal, falta o deficiencias en la supervisión del personal y de las transacciones, escaso interés de la alta dirección y de los órganos de gobierno por implementar procedimientos de control interno eficaces, presión excesiva por alcanzar metas presupuestales o de resultados, falta de monitoreo y verificación de procesos relevantes y críticos en las compañías, entre otros.

Por desgracia, ningún tipo y tamaño de empresa está exenta de ser víctima de fraude, ya que, de acuerdo con estudios realizados, los fraudes han sido perpetrados en compañías de sectores financieros, de construcción, industria manufacturera, comercio al mayoreo y menudeo, tecnologías, telecomunicaciones, etc., lógicamente los daños ocasionados han sido mayores 
en organizaciones medianas y grandes, pero todas, sin excepción, han resentido las consecuencias nocivas de los fraudes (Baza, 2016, párr. 2).

Dada las condiciones que anteceden, los delitos económicos son cometidos generalmente por personas que tienen un alto grado de inteligencia, confianza, tiempo, técnicas, recursos, información acerca de la empresa y hasta alianzas que saben aprovechar muy bien para sacar provecho o ventaja propia, prevaleciendo siempre el interés personal antes que el general, maximizando sus ganancias, sin importar el bienestar social.

Finalmente, en la actualidad, existen múltiples formas de delinquir en las empresas tanto a nivel administrativo como operativo, algunas actividades que pueden ser de especial cuidado son: manipulación de documentos, extravío o desviación de ingresos, pasivos inexistentes, manipulación de contratos y contrataciones, utilización de testaferros, exportaciones ficticias, lavado de activos, maquillaje de información financiera, patrimonios sobrevalorados, patrimonios subvalorados, ventas ficticias entre vinculados, alteración de registros, apropiación indebida de recursos de la empresa, jineteo de recursos, transacciones inexistentes, pagos dobles, ocultamiento de activos, pasivos, ingresos, gastos; clientes falsos, compras no existentes, pérdidas o ganancias simuladas, compras irreales, registro de facturas personales, registro de ventas por valores inferiores a los realmente recibidos, robo de inventarios, ventas ficticias para cobro de comisiones a la empresa, cobrar sueldos de empleados que salieron de la organización o que nunca existieron (Sadder, 2013).

Durante el proceso de comprobación de los hechos delictivos, es importante que el auditor forense pueda establecer los siguientes aspectos (qué sucedió, cómo sucedió, dónde sucedió, por qué sucedió, cuándo sucedió y quién lo realizó), adicionalmente se debe tener una visión de los escenarios delincuenciales (informáticos, balances fraudulentos, manejo, gestión y directrices gerenciales, entre otros) y valorar los elementos materiales de prueba que generen un concepto que sirva como medio probatorio en la corte. «Pero aquella información suministrada por el auditor forense para tener legalidad ante la corte debió haberse manejado bajo el concepto de cadena de custodia que se define como proceso ordenado para entregar, evaluar y presentar las evidencias obtenidas» (Villalobos, 2010, p. 13).

\section{Conclusiones}

- La auditoría forense surge como una necesidad de descubrir y/o controlar el aumento del crimen económico y financiero en las organizaciones, hoy en día esta es una especialización de la contaduría importante, considerando que permite detectar posibles fraudes y recolectar las pruebas que le dan las claridades suficientes al juez, para determinar la pena o castigo para este delito; igualmente le consiente realizar procesos de prevención, recomendación de acciones o controles en los entes económicos, teniendo en cuenta que los actos ilícitos o el mal uso de los recursos, además de muchos daños económicos y sociales a las empresas, logran incluso llevarlas a la quiebra.

El contador público forense, que ha sido contratado para dar trámite a una investigación de actos ilícitos, necesita tener una conducta ética, ser una persona integral, puesto que tiene la responsabilidad de investigar la existencia de los mismos y proporcionar los elementos y pruebas suficientes que permitan a las autoridades 
competentes establecer la existencia o no del delito económico o financiero. Por lo tanto, es de su competencia desarrollar y aplicar cualidades y conocimientos profesionales y personales necesarios durante las prácticas desarrolladas en el proceso de la investigación. Es fundamental desarrollar habilidades para detectar los posibles casos de incorrección material en la información que se audita, y para ello no solo es indispensable saber de contabilidad, también de otros conocimientos complementarios que le permitan detectar con facilidad la existencia de delitos cometidos en las empresas.

- Para hacer parte del mundo globalizado y tener la posibilidad de enfrentar nuevos mercados internacionales, se debe tener en cuenta el cumplimiento de estándares y normas que permitan mejorar la calidad de la información. El contador público forense requiere convertirse en un profesional competitivo, planear e impulsar estrategias y realizar cambios trascendentales a nivel de capacitación y formación profesional que lo hagan ser parte activa del proceso, buscar e implementar alternativas que lo mantengan vigente en el mercado profesional forense.

El auditor forense encuentra en la adopción de las NIIF y las NIA, un apoyo o herramienta que le facilita identificar los posibles riesgos de hechos ilícitos en la organización, esto se logra a través del conocimiento de la misma y su entorno, mediante una observación bajo el escepticismo profesional, y obteniendo la información necesaria, precisa, suficiente y de las mejores fuentes, para lograr el conocimiento absoluto de todo lo referente a la entidad que va a auditar. No confiar plenamente en los datos que le suministran, porque pueden contener errores intencionales o no, que alteran el juicio profesional.

Cuando se provee de unos datos transparentes y sin sesgo, se convierten en un valioso recurso para quienes son responsables de la toma de decisiones, con la seguridad de que los informes que se entregan representan fielmente la situación económica de la empresa, y que se puede tener plena credibilidad en ella.

- Es necesario identificar y descubrir cuáles son los posibles riesgos que existan de actos delictivos que infringen la ley, esto se puede hacer a través del análisis de las personas, de procedimientos, de operaciones, de procesos, entre otros.

- La comunicación de resultados debe ser entendible, confiable, coherente, basada totalmente en el trabajo de observación realizada, con sus conclusiones y recomendaciones que permitan a la justicia tomar las mejores decisiones acerca del caso.

- El auditor forense demanda estar actualizado en vista de que frecuentemente se expiden y estandarizan normas y leyes, no solo de tipo penal, igualmente, comercial, contable, tributario, etc. Es primordial para el desarrollo de su especialidad estar al día en diferentes temas, para mantenerse así vigentes en el mercado y desarrollar su profesión de acuerdo con las exigencias del mismo.

\section{Referencias}

- Arroyo, A. (2011). Normas Internacionales de Información Financiera y el Peritaje Contable. Contabilidad y Negocios, (6), 67-81. 
- Badillo, J. (2008). Auditoría Forense. Recuperado de www.theiia.org/chapters/pubdocs/70766573/Auditoría.pdf

- Baracaldo, N.A. (2013). ¿Es garante del principio de transparencia la implementación de normas internacionales en Colombia? Cuaderno de Contabilidad, (36), 1097-1120.

- Baracaldo, N.A. y Daza, L.E. (s.f). La importancia de la auditoría forense en la investigación de fraudes y delitos financieros. IV encuentro nacional de profesores de Contaduría Pública. Recuperado de http://www. conveniocpc.org/images/Memorias_iv_encuentro/Mesa_Auditoría/Importancia_de_ la_Auditoría_Forense.pdf.

- Baza, F. (2016). Fraude: Efectos en la auditoría de estados financieros. Recuperado de https://auditool.org/blog/auditoria-externa/3597-fraude-efectos-en-la-auditoria-de-estados-financieros

- Fonseca, V.A. (2009). Auditoria Forense Aplicada a la tecnología. Adversia, Revista virtual. Recuperado de http://aprendeenlinea. udea.edu.co/revistas/index.php/adversia/ article/viewArticle/4770.

- Funes, Y. \& Najera, A.L.. (s.f). Propuesta de una metodología para llevar a cabo la auditoría forense. Decimoquinto congreso Internacional de Contaduría, Administración e Informática. Universidad Autónoma de México.

- González, S., Giménez, M., Puyó, V., Padovan, A., Stefanon, G., y Villani, S. (2011). El enfoque de riesgo en la auditoría. Recuperado de http://docplayer.es/15288827-Elenfoque-de-riesgo-en-la-auditoria.html
- Hernández, J. (2012). GIC El Salvador. Grupo de investigación contable. Recuperado de https://grupodeinvestigacioncontable.blogspot.com/2012/03/uso-del-blog-d.html

Herreros, J. (2010). Normas Internacionales de Auditoría: principales impactos del Proyecto Clarity. Partida doble, (224), 69-79.

- Ley 1314. (2009). Por la cual se regulan los principios y normas de contabilidad e información financiera y de aseguramiento de información aceptados en Colombia. Recuperado de http://www.alcaldiabogota.gov. co/sisjur/normas/Norma1.jsp?i=36833

- Ley 43. (1990). Reglamentaria de la profesión de Contador Público y se dictan otras disposiciones. Recuperado de https:// www.mineducacion.gov.co/1621/articles-104547_archivo_pdf.pdf

- Londoño, A.E. y Saldarriaga, V. (2011). La auditoría forense: un campo en potencia. $A d-$ versia Universidad de Antioquia, (8), 55-66.

- Maiola, O. y Saldarriaga, V. (2013). El fraude y los controles en los sistemas contables. Contabilidad y Auditoría Investigaciones en Teoría Contable, (38), 1-51.

- Martínez, F.J., Ramírez, S.I., Montoya, J., y Fernández, A. (2010). La importancia relativa en auditoría. Las nuevas normas internacionales en comparación con la normativa vigente en Iberoamérica. Contaduría y Administración, (230), 77-103.

Ochoa, L.M, Zamarra, J.E. y Castaño, C.E. (2012). Caracterización de las mejores prácticas para la detección de fraude en una auditoría de estados financieros: análisis del caso colombiano. XIII Asamblea General de 
Asociación Latinoamericana de Facultades y Escuelas de contaduría y Administración, Buenos Aires - Argentina.

- Pantoja, J. (2012). ¿Quién ejerce la auditoría forense en los delitos económicos y financieros? Tendencias, (13), 241-250.

- Ramírez, M y Reina, J. (2013). Metodología y desarrollo de la auditoría forense en la detección del fraude contable en Colombia. Cuadernos de Administración, (29), pp. 186-195.

- Sadder, Y. P. (2013). Ensayo - La auditoría forense como herramienta para prevenir el fraude financiero. Militar Nueva Granada. Recuperado de http://hdl.handle. net/10654/11142
- Sánchez, C.A. (2012). Dirección General de Educación a distancia. Facultad de Contaduría pública, Especialización en Contraloría Integral, Corporación Universitaria Remington.

- Villalobos, C. (2010). La auditoría forense como herramienta de ayuda en la detección de actos de corrupción en las empresas del sector público de la ciudad de Cartagena. Revista Aglala, (1),1-153. 